\title{
Universiteit
}

Leiden

The Netherlands

\section{Diet rich in a-lactalbumin improves memory in unmedicated recovered depressed patients and matched controls}

Booij, L.; Merens, W.; Markus, C.R.; Does, A.J.W. van der

\section{Citation}

Booij, L., Merens, W., Markus, C. R., \& Does, A. J. W. van der. (2006). Diet rich in alactalbumin improves memory in unmedicated recovered depressed patients and matched controls. Journal Of Psychopharmacology, 20, 526-535. Retrieved from https://hdl.handle.net/1887/14418

Version: $\quad$ Not Applicable (or Unknown)

License: $\quad$ Leiden University Non-exclusive license

Downloaded from: https://hdl.handle.net/1887/14418

Note: To cite this publication please use the final published version (if applicable). 


\title{
Diet rich in $\boldsymbol{\alpha}$-lactalbumin improves memory in unmedicated recovered depressed patients and matched controls
}

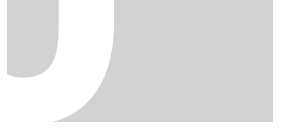 \\ Journal of Psychopharmacology \\ 20(4) (2006) 526-535 \\ (c) 2006 British Association \\ for Psychopharmacology \\ ISSN 0269-8811 \\ SAGE Publications Ltd, \\ London, Thousand Oaks, \\ CA and New Delhi \\ $10.1177 / 0269881105057466$
}

\author{
Linda Booij Department of Psychology, Leiden University, Leiden, The Netherlands. \\ Wendelien Merens Department of Psychology, Leiden University, Leiden, The Netherlands. \\ C. Rob Markus Faculty of Psychology, Maastricht University, Maastrict, The Netherlands.
}

A. J. Willem Van der Does Department of Psychology, Leiden University and Department of Psychiatry, Leiden University Medical Center, Leiden, The Netherlands.

\begin{abstract}
Depression is associated with reduced brain serotonin (5-hydroxytryptamine; 5-HT) function and with cognitive dysfunctions. A diet rich in $\alpha$-lactalbumin protein has been found to increase the ratio tryptophan /large neutral amino acids (Trp/ $\sum$ LNAA), and to improve cognitive functioning in individuals with high neuroticism scores. Since cognitive dysfunctions sometimes persist after remission of depression, the present study investigated the effects of $\alpha$-lactalbumin-enriched diet on cognition in recovered depressed patients.

Twenty-three recovered depressed patients and 20 healthy matched controls without a history of depression consumed meals rich in $\alpha$ lactalbumin or casein protein in a double-blind crossover design. Mood, cognitive function and plasma amino acids were assessed at both sessions before and after dietary intake.
\end{abstract}

\begin{abstract}
Alpha-lactalbumin protein had no effect on mood, but improved abstract visual memory and impaired simple motor performance. These effects were independent of history of depression. Supplements of $\alpha$ lactalbumin may be useful for nutrition research in relation to age- or disease-related memory decline. The present findings should be further examined in different (e.g. medicated) samples. The long-term effects of $\alpha$-lactalbumin should also be investigated.
\end{abstract}

\section{Keywords}

serotonin, depression, cognition, memory, tryptophan, alpha-lactalbumin

\section{Introduction}

Depression is associated with impaired cognitive functioning (Austin et al., 2001). Impaired spatial and verbal memory has most frequently been reported (Burt et al., 1995: review). However, deficits in other domains are also common, including psychomotor skills, attention and executive functioning (Austin $e t$ al., 2001). Mild deficits often persist after remission (Paradiso et al., 1997), irrespective of residual symptoms (Weiland-Fiedler et al., 2004) or medication status (Paradiso et al., 1997).

The serotonin (5-hydroxytryptamine; 5-HT) system is important in the regulation of mood as well as cognitive functions. Selective serotonin reuptake inhibitors (SSRIs) are found to relieve depressive symptoms and to enhance memory function in humans and rats (McEntee and Crook, 1991). Conversely, experimental depletion of L-tryptophan (the precursor of serotonin) induces depressive symptoms in depression-vulnerable individuals (see for reviews: Booij et al., 2003; Van der Does 2001) and impairs longterm memory in healthy volunteers (Riedel et al., 1999; Schmitt et al., 2000). The effects of enhanced 5-HT activity on cognitive processes have frequently been investigated by using low protein diets that consist almost entirely of carbohydrates. These diets increase the amount of plasma tryptophan (Trp) as compared to the other large neutral amino acids (ratio Trp/LLNAA) that competes with Trp for uptake into the brain (Fernstrom and Wurtman, 1972). High-carbohydrate meals have been found to improve cognitive performance in both clinical and healthy populations, but the results are not consistent (see for reviews: Benton and Nabb, 2003; Dye et al., 2000; Gibson and Green, 2002). These inconsistent results may be related to the timing of intervention or the 
amount of carbohydrates consumed. Furthermore, individual differences in stress-vulnerability may be involved, as carbohydrates improved mood and information processing in high stress-prone but not in low stress-prone healthy individuals (Markus et al., 1998). The use of carbohydrate-rich meals poses methodological difficulties, including lack of a placebo condition and expectancy effects (Dye et al., 2000; Gibson and Green; 2002; Spring et al., 1987). Besides, a very large amount of carbohydrates, and consequently high-caloric meals may be needed to produce biochemical and behavioral changes, making implementation in a regular diet undesirable.

A different method to enhance Trp availability involves using $\alpha$-lactalbumin protein (Markus et al., 2000, 2002). Alpha-lactalbumin protein has the highest L-tryptophan concentration of all protein fractions (Heine et al., 1996). A diet enriched with $\alpha$-lactalbumin increased the ratio plasma Trp/ 2 LNAA by $46-48 \%$ in healthy volunteers, as compared to casein (placebo). This effect is two times higher than the effect generally found after a carbohydrate-rich diet (Markus et al., 2000), or after 7 days of daily treatment with L-tryptophan (Chouinard et al., 1985). Alphalactalbumin improved mood and information processing, and attenuated stress-induced cortisol-responses in stress-vulnerable subjects (non-patients with high neuroticism scores) but not in controls (low neuroticism scores) (Markus et al., 2000, 2002). These data suggest that enhancing 5-HT function through diet may be particularly beneficial for vulnerable individuals under high levels of stress and may improve stress coping.

In the present study we were particularly interested in investigating the cognitive effects of $\alpha$-lactalbumin in recovered depressed patients and matched controls. Since cognitive dysfunctions may persist after remission, we expected to find residual cognitive impairments at baseline in recovered depressed patients relative to controls. Furthermore, we expected that $\alpha$-lactalbumin would improve cognitive function compared to a casein diet, and that the effects of $\alpha$-lactalbumin would be more pronounced in recovered depressed patients than in controls. We have previously reported that $\alpha$-lactalbumin did not change mood or cortisol response following laboratory stress in recovered depressed patients or controls (Merens et al., 2005). However, cognitive effects in the absence of mood effects have regularly been reported after manipulations of neurotransmitters, e.g. tryptophan depletion (Booij et al., 2005a; 2005b) or a single dose of an antidepressant (Harmer et al., 2002; 2003).

\section{Methods and materials}

\section{Participants}

Twenty-three recovered depressed patients (21 females and two males) and 20 controls (17 females and three males) participated in the study. Some of the patients were former participants of a randomized psychotherapy trial, whereas additional patients and all controls were recruited via advertisements at Leiden University or in local newspapers. Inclusion criteria were: age between 18 and 65; meeting DSM-IV criteria for history of depression (patient group only); free of antidepressant medication for at least 3 months; no history of psychiatric disorders and having no firstdegree relative of major depressive disorder (control group only); no current psychiatric disorder; Montgomery-Asberg Depression Rating Scale lower than eight (Montgomery and Asberg, 1979) and a Body Mass Index (BMI in $\left.\mathrm{kg} / \mathrm{m}^{2}\right)$ above 18. Exclusion criteria were: substance abuse within last 3 months, psychosis (lifetime), major physical illness, lactation, pregnancy and excessive dieting or binge eating. Diagnoses, demographic and clinical background variables were verified by means of the Structured Clinical Interview for DSM-IV (SCID-I) (First et al., 1995)

\section{Composition of the diet}

At each session, participants received a carbohydrate-rich breakfast and lunch. The energy intake per session totalled $294 \mathrm{kcal}$ $(1229 \mathrm{~kJ})$, of which $21.4 \%$ was from fat, $75.4 \%$ as carbohydrates and $4.6 \%$ as protein. Each breakfast and lunch consisted of one slice of bread, $10 \mathrm{~g}$ butter, $15 \mathrm{~g}$ fruit jelly, grape juice $(200 \mathrm{ml})$ and a chocolate drink. The two diets were identical with the exception of the composition of a chocolate drink in which the protein sources differed. The chocolate drink in the $\alpha$-lactalbumin diet contained a whey-protein fraction rich in $\alpha$-lactalbumin (containing $12.32 \mathrm{~g} / \mathrm{kg}$ Trp; Trp/ $/$ LNAA ratio of 8.7) and the chocolate drink in the control diet contained sodium caseinate (containing $9.51 \mathrm{~g} / \mathrm{kg}$ Trp, Trp/ $/$ LNAA ratio of 4.7). The composition and preparation of the chocolate drinks were similar in appearance and macronutrient composition as in Markus et al. $(2000,2002)$. Other nutrients or drinks were not allowed until the end of session, except for water during the whole day and one cup of coffee or tea without milk $+1.25 \mathrm{~h}$ after breakfast.

\section{Instruments}

Mood Changes in mood were measured using the Dutch shortened paper and pencil version of the Profile of Mood States questionnaire (POMS) (McNair et al., 1971; Wald et al., 1990). The POMS comprises five different subscales for mood. The subscale Anger (range: 0-28), Depression (range: 0-32), Fatigue (range: $0-24$ ) and Tension (range: $0-24$ ) refer to a negative mood state, whereas the subscale Vigour (range: 0-20) concerns a positive mood.

Personality Neuroticism (N) was measured with the shortened Eysenck Personality Questionnaire (EPQ-RSS) (Eysenck and Eysenck, 1991). The Dutch translation (Sanderman et al., 1995) was used, which has different norms from the original (about 1.5 points lower). According to the manual, the mean $\mathrm{N}$ score of the general population is around four. Norms for psychiatric patients are not available; however we found a mean $\mathrm{N}$ score of 6.4 (S.E. 0.55 ) in a recent study of 39 (partially) remitted depressed outpatients (who were in treatment and who had a mean of 4.4 past episodes of depression) (Van der Does and Booij, 2005). 


\section{Cognition}

\section{Sternberg Memory Scanning Task}

The computerized Memory Scanning Task is based on the information processing model of Sternberg, who distinguishes scanning and non-scanning stages of information processing (Sternberg, 1969). The Memory Scanning Task consisted of three trials, corresponding to a set of two, three or six consonants respectively. In each trial, the set of letters is presented in the middle of the screen, and the participant was instructed to memorize them ('memory' set). After memorization, 90 letters in each trial are presented on the screen in a random order one by one for $1500 \mathrm{~ms}$ each at an interval range of $500 \mathrm{~ms}$. Fifty percent of the letters presented belonged to the memory set and 50\% did not. Participants were instructed to push on the 'yes' button if the letter presented belonged to the memory set of that condition and on the 'no' button when it did not. Reaction times and number of errors for each condition were the outcome measures of this test.

\section{Abstract Patterns Recognition Task (APRT)}

The APRT modelled after Rubinsztein et al. (2001) measures (speed of) retrieval of non-verbal abstract information from shortterm memory (STM) and long-term memory (LTM). Sixteen abstract patterns were presented consecutively for $3000 \mathrm{~ms}$, with $500 \mathrm{~ms}$ intervals. Participants were instructed to memorize the patterns. After three presentations of the complete series, two patterns were presented simultaneously; one that had been learned and a new pattern. Participants had to indicate as fast as possible which one had been previously presented. The recognition procedure was repeated after 35 minutes, during which verbal tasks were administered.

Sensitivity measures (A') were calculated for the proportion of correctly recognized patterns, corrected for response tendency by the formula: $\mathrm{A}^{\prime}=1-1 / 4(\mathrm{fr} / \mathrm{cr}+(1-\mathrm{cr}) /(1-\mathrm{fr}))$, in which $\mathrm{fr}=$ the proportion of falsely recognized patterns and $\mathrm{cr}=$ proportion of correctly recognized patterns (signal detection theory; Pollack and Norman, 1964).

\section{Stroop Colour Word Task (SCWT)}

The Stroop test measures focused attention and response inhibition. Names of colours (red, yellow, blue, green) printed in black were presented one by one for a maximum of $1500 \mathrm{~ms}$ on a computer screen. Participants were instructed to read these words as fast as possible (Condition I). Next, coloured patches were presented (Condition II) of which the name of the colour had to be named. Finally, names of colours printed in an incongruent colour were presented and participants were instructed to name the colour of the ink (Condition III). Median reaction times (RTs) and errors were recorded. Interference was defined as the percentage of extra time needed for condition III relative to the average of conditions I and II.

\section{Left/right choice reaction time}

This task was used to assess motor speed and response inhibition as a function of task difficulty. The word 'left' or 'right' was presented in randomized order either at the left or the right side of the screen. Participants were instructed to respond to the meaning of the word while ignoring its location, as fast as possible. The task consisted of two consecutive subtasks in which the stimulus interval differed ( $1000 \mathrm{~ms}$ fixed vs. $500-1500 \mathrm{~ms}$ variable). Correct responses and RTs were registered.

\section{Tower of London (TOL)}

The TOL modelled after Owen et al. (1995) is a planning task consisting of three coloured balls (red, yellow and blue) placed on three sticks in various arrangements. Two arrangements were presented on the upper and lower half of the screen. The patient was instructed to indicate the minimal number of moves necessary to change the first arrangement into the second (two to five moves). Correct responses and RTs were registered.

\section{Blood plasma}

A blood sample was obtained $(10 \mathrm{ml})$ using EDTA tubes to determine total plasma Trp and the other large neutral amino acids (tyrosine, phenylalanine, isoleucine, leucine and valine). Immediately after sampling, the blood was centrifuged for 20 minutes at $2650 \mathrm{~g}_{\max }$ and the plasma was stored at $-20{ }^{\circ} \mathrm{C}$. Quantitative amino acid analysis was performed by an ion-exchange chromatography on a Biochrom 20 automated amino acid analyser (Pharmacia) as described elsewhere (Merens et al., 2005).

\section{Design and procedure}

The study was conducted according to a randomized double-blind crossover design with two experimental sessions. One week before the first experimental session, after receiving oral and written information about the study and providing written informed consent, potential participants were invited to a screening interview that included the Structured Clinical Interview for DSM-IV (SCID) (First et al., 1995), Montgomery-Asberg Depression Rating Scale (MADRS) (Montgomery and Asberg, 1979), the Beck Depression Inventory-II (BDI-II) (Beck et al., 1996) and a medical examination. The SCID and the MADRS interviews were conducted by trained clinical psychologists. In addition, the cognitive test battery was administered.

During the experimental sessions, participants came to the laboratory at 8 or 9 AM $(-1 \mathrm{~h})$ after an overnight fast. Baseline mood was measured with the POMS and a first blood sample was obtained, followed by administration of cognitive tasks. The cognitive test battery took 45 minutes. Next, participants ate breakfast, including a drink containing either tryptophan-rich $\alpha$-lactalbumin or casein $(0 \mathrm{~h})$. Lunch, at $+2 \mathrm{~h}$, also contained either an $\alpha$-lactalbumin or casein drink. A second blood sample was taken at $+3.5 \mathrm{~h}$, followed by the POMS and cognitive tests at $+3.75 \mathrm{~h}$. Participants were tested individually, and remained in a private research room between assessments.

The order of presentation of the $\alpha$-lactalbumin and casein diets was counterbalanced. Both experimental sessions were separated by exactly four weeks. Pre-menopausal women not taking a contraceptive pill were tested during their mid-to-late follicular phase (days 4-10), whereas pre-menopausal women taking the contraceptive pill participated during the period in which they actually took the contraceptive pill. All participants were paid $€ 80$ for participation. The study was approved by the Medical Ethics Committee of Leiden University Medical Center. 


\section{Statistical analysis}

Prior to analysis, all variables were examined for accuracy of dataentry, missing values and fit between their distributions and the assumptions of the statistical analyses. Group differences in demographic characteristics, baseline mood ratings and cognitive performance were examined by means of chi-square statistics and multivariate analyses of variance (MANOVA) by using the General Linear Model (GLM: SPSS 11.5 for Windows, SPSS Inc, Chicago). RTs of the TOL and Left/Right task were $\log _{10}$ transformed prior to analysis. POMS scores were analysed with nonparametric statistics because transformations were unsuccessful, as shown by visual inspection and Shapiro Wilk statistics (Stevens, 1996).

The effects of the interventions on cognitive tests and biochemical outcome measures were analysed by separate repeated measure multivariate analyses of variance, using Intervention $(\alpha-$ lactalbumin $v s$. casein) and Time (before vs. after intervention) as within-subjects factors and Group (recovered depressed patients $v s$. controls) as between-subjects factor. Thus Intervention $\times$ Time and Intervention $\times$ Time $\times$ Group interactions reflected the main effects of interest. Level of difficulty was added as a within-subjects factor for the Memory Scanning Task (three levels) and Tower of London (four levels); whereas the Left/Right tasks consisted of an additional level 'condition' (congruent $v s$. incongruent). Significant results revealed by these procedures were further examined by post hoc tests. Although we counterbalanced for order of intervention, we first conducted analyses with order of intervention as a covariate. However, order of intervention did not contribute to any of the effects. All statistics were evaluated at a significance level of $5 \%$.

\section{Results}

\section{Data screening/drop-outs}

Of a total of 49 participants who were included, 43 (23 recovered depressed patients; 20 controls) completed the study. Three recovered depressed patients were included but decided not to participate. Three patients dropped out after the first session; the first case due to nausea (after $\alpha$-lactalbumin), the second case dropped out because of feeling uncomfortable with venapunction during the first session (casein); the third one could not be contacted to schedule the second session on time (casein). These patients were left out of all analyses.

Due to a computer failure, data of the cognitive tasks during the screening session for one control patient were lost. For one patient, data of the Memory Scanning task during the screening session were missing. TOL data during the screening session were missing for another patient. Morning assessments of the Left/Right task in the casein condition were unavailable for one patient. Twenty-two of the 172 blood samples (12.7\%) were missing because of difficulties with the venapunction. Cases with missing data were omitted separately by analysis.

\section{Participants, baseline cognitive performance}

Clinical and demographic characteristics are shown in Table 1.

Recovered depressed patients ('recovered MDD') did not differ from the participants with no history of depression ('controls') in terms of gender distribution, age and education level, indicating that matching was successful. BDI-II scores were higher in the patient group than in controls $[F(1,41)=7.31 ; p=$ 0.01; however, BDI-II scores are low and well within the normal range in both groups. There were no group differences on any of the cognitive tasks conducted during the screening session or in the morning sessions of both conditions. Controlling data for group differences in BDI-II scores did not change these results.

\section{Dietary effects on amino acids}

Repeated measures analyses for Trp/ 2 LNAA with intervention and time as within-subjects factors and group as between-subjects factors revealed a main effect of intervention $[F(1,29)=84.39$; $p<0.001]$, time $[F(1,29)=7.08 ; \mathrm{p}=0.01]$ and a significant interaction between intervention and time $[F(1,29)=193.28$; $p<0.001]$. Trp/ $\sum$ LNAA increased significantly by $20.9 \%$ compared to baseline after the $\alpha$-lactalbumin-diet and decreased by $30.0 \%$ after the casein diet. After $\alpha$-lactalbumin, the $\operatorname{Trp} / \sum$ LNAA ratio was $71.5 \%$ higher than after casein. After $\alpha$-lactalbumin, Trp levels increased $77.5 \%$ relative to baseline and were $54.0 \%$ higher

Table 1 Characteristics of the investigated sample

\begin{tabular}{|c|c|c|}
\hline & $\begin{array}{l}\text { Recovered MDD } \\
(N=23)\end{array}$ & $\begin{array}{l}\text { Controls } \\
(N=20)\end{array}$ \\
\hline Mean age in years $\pm S D$ & $29.96 \pm 9.7$ & $26.95 \pm 10.1$ \\
\hline Female & $n=21$ & $n=17$ \\
\hline Body Mass Index $(B M I)\left(\mathrm{kg} / \mathrm{m}^{2} \pm S D\right)$ & $22.84 \pm 2.5$ & $21.69 \pm 2.1$ \\
\hline \multicolumn{3}{|l|}{ Education level } \\
\hline $\operatorname{High}^{1} /$ Medium $^{2} /$ Low $^{3}$ & $1 / 14 / 7$ & $1 / 12 / 7$ \\
\hline MADRS & $1.30 \pm 1.6$ & $0.80 \pm 1.6$ \\
\hline BDI-II & $4.43 \pm 4.5$ & $1.45 \pm 2.2$ \\
\hline Number of previous episodes & $2.00 \pm 0.9$ & \\
\hline - Single episode & $n=7$ & \\
\hline - Multiple episodes & $n=15$ & \\
\hline Age of onset first episode $\pm S D$ & $19.91 \pm 7.7$ & \\
\hline \multicolumn{3}{|l|}{ History of treatment: } \\
\hline - SSRI & $n=1$ & \\
\hline - Psychotherapy & $n=7$ & \\
\hline - SSRI + Psychotherapy & $n=5$ & \\
\hline - Alternative treatment & $n=3$ & \\
\hline - Spontaneous recovery & $n=7$ & \\
\hline
\end{tabular}

${ }^{1}$ Higher vocational education, university; ${ }^{2}$ Secondary education, medium and higher level or senior secondary vocational education; ${ }^{3}$ Primary education, secondary education lower level. MADRS = Montgomery-Asberg Depression Rating Scale; BDI-II = Beck Depression Inventory, 2nd edition; SSRI = selective serotonin reuptake inhibitor. 
than after casein $(p<0.001)$. There were no group or baseline differences in plasma Trp or ratio Trp/LLNAA. Repeated measures analyses for tyrosine/ $\sum$ LNAA revealed a main effect of intervention $[F(1,29)=22.51 ; p<0.001]$, time $[F(1,29)=8.14$; $p=0.01]$ and a significant interaction between intervention and time $[F(1,29)=123.59 ; p<0.001]$. Compared to baseline levels, tyrosine/ $\sum$ LNAA decreased $11.5 \%$ in the $\alpha$-lactalbumin condition and increased $28.1 \%$ in the casein condition. After casein, the Tyrosine $/ \sum$ LNAA ratio was $35.8 \%$ higher than after $\alpha$-lactalbumin.

\section{Mood}

POMS depression scores (mean $\pm \mathrm{SE}$ ) in the $\alpha$-lactalbumin session changed from $0.74 \pm 0.29$ to $0.17 \pm 0.14$ for the recovered MDD group. The mean \pm SE for the control group in the $\alpha$-lactalbumin session on that scale was $0.00 \pm 0.00$ both before and after intervention. POMS depression scores in the casein condition changed from $1.00 \pm 0.47$ to $0.17 \pm 0.10$ for the recovered MDD group and from $0.30 \pm 0.16$ to $0.00 \pm 0.00$ for the control group. Non-parametric tests did not reveal a significant group or intervention effect on any POMS subscale.

\section{Cognition}

Multivariate analysis of variance revealed an intervention * time interaction for the outcome measures of the APRT $[\mathrm{F}(4,38)=3.06$; $p=0.03]$. Further univariate tests revealed significant intervention * time interactions for the STM measures $\mathrm{A}^{\prime}[F(1,41)=5.99 ; p=$ $0.02]$ and RT $[F(1,41)=4.07 ; p=0.05]$ and also for LTM-RT $[F(1,41)=4.49 ; p=0.04]$, but not for LTM-A' $[F(1,41)=0.08 ; p$ $=0.78]$ (Figures 1 and 2). $\alpha$-lactalbumin diet improved the number of correctly recognized abstract pictures and improved speed of recognition from STM and LTM, but there were no group differences, as shown by nonsignificant intervention * time * group interactions for STM-A' $[F(1,41)=2.04 ; p=0.16]$, STM-RT $[F(1,41)$ $=0.53 ; p=0.47]$ and LTM-RT $[F(1,41)=2.26 ; p=0.14]$. The interaction for LTM-A' was statistically a trend $[F(1,41)=3.08 ; p$ $=0.09$ ]. To further explore the effects as shown in Figures 1 and 2, separate analyses were conducted for the recovered MDD and control group. These should be interpreted with caution however because of an absence of an interaction with group in the primary analyses of interest. In the recovered MDD group, significant intervention * time interactions were found for STM-A' $[F(1,22)=$ 9.09; $p=0.006]$, LTM-RT $[F(1,22)=4.64 ; p=0.04]$, and a trend for LTM-A' $[F(1,22)=2.89 ; p=0.10]$. The intervention * time interaction for STM-RT was not significant $[F(1,22)=0.70 ; p=$ $0.41]$, whereas this interaction was the only significant interaction in the control group $[F(1,19)=5.07 ; p=0.04]$.

For the Left/Right task, there was a multivariate significant intervention * time $*$ group effect $[F(2,39)=4.12 ; p=0.02]$, due to a group difference in the subtask with variable stimulus intervals $[F(1,40)=7.78 ; p=0.01]$. Separate analysis for the recovered MDD group and the control group showed that controls became faster after $\alpha$-lactalbumin condition relative to casein condition, whereas the reverse pattern occurred in the recovered MDD group. Using a similar double multivariate repeated measures design, the number of errors increased in the $\alpha$-lactalbumin condition relative to casein condition, as shown by an intervention * time interaction effect $[F(2,39)=3.47 ; p=0.02]$. Univariate tests showed that this was true for the fixed interval subtask $[F(1,40)=$ $6.87 ; p=0.01]$. There were no higher order interactions with group.

On the Memory Scanning Task, there was an overall multivariate main effect of memory set on total reaction time $[F(2,40)=$ $81.34 ; \mathrm{p}<0.001]$ and number of errors $[F(2,40)=18.33$; $\mathrm{p}<0.001]$, indicating that the time to respond and the number of errors increased when the memory set becomes larger. A similar pattern was found for the TOL, with slower responses $[F(3,36)=$ $173.53 ; \mathrm{p}<0.001]$ and a higher number of errors $[F(3,36)=43.85$; $\mathrm{p}<0.001]$ as the task became more difficult.

There were no intervention * time, intervention * time * group on the Memory Scanning Task, Stroop Task and TOL (Table 2).

\section{Discussion}

The aim of this study was to investigate whether increased Trp availability after $\alpha$-lactalbumin diet affects cognitive function, particularly in recovered depressed patients. The $\alpha$-lactalbumin diet increased plasma Trp/ $/$ LNAA ratio (21\% increase from morning to afternoon; afternoon ratio $71.5 \%$ higher than in the placebo condition). Memory performance after $\alpha$-lactalbumin improved in both groups, and no other reliable effects were found.

\section{Baseline cognitive performance in recovered depressed patients vs. controls}

Unexpectedly, no baseline differences in cognitive performance were found between recovered depressed patients and controls. Using the same cognitive tests, our previous study in remitted depressed patients showed impaired abstract long-term visual memory at baseline relative to controls (Booij et al., 2005b). This result is also in contrast with other studies that found residual cognitive impairments in short-term memory, attention and executive functioning in recovered depressed patients (e.g. Paradiso et al., 1997). One likely explanation for this difference might be that the recovered MDD group in the present study was much younger (30.0 years) than in our previous study (48.7 years) or in Paradiso et al. (55.9 years), with about one third of the individuals having experienced a single episode during late adolescence rather than multiple episodes. Cognitive impairments in the recovered phase may be more severe in patients with recurrent episodes than in those with a single episode (Kessing, 1998).

\section{Dietary effects on cognitive performance}

The $\alpha$-lactalbumin diet improved abstract visual memory in both recovered depressed patients and controls. More specifically, $\alpha-$ lactalbumin improved recognition and speed of retrieval from short- and long-term abstract visual memory. Overall, there was no interaction with group. There were no effects on the TOL, Memory Scanning Task and Stroop Task, indicating that $\alpha$-lactalbumin did not change the encoding phase, working memory, 
Table 2 The Means (SE) of the cognitive tasks as a function of group, time and intervention

\begin{tabular}{|c|c|c|c|c|c|}
\hline \multirow[b]{2}{*}{ Cognitive test } & \multirow[b]{2}{*}{ Diet } & \multicolumn{2}{|c|}{ Recovered MDD $(n=23)$} & \multicolumn{2}{|c|}{ Controls $(n=20)$} \\
\hline & & Before diet & After diet & Before diet & After diet \\
\hline \multicolumn{6}{|l|}{$\begin{array}{l}\text { Memory Scanning } \\
\% \text { correct }\end{array}$} \\
\hline \multirow[t]{2}{*}{2 letters } & $\alpha-\operatorname{lac}$ & $97.6(0.5)$ & $98.0(0.4)$ & $97.8(0.3)$ & $97.1(0.4)$ \\
\hline & casein & $98.1(0.4)$ & $98.4(0.3)$ & $96.9(0.5)$ & $97.2(0.3)$ \\
\hline \multirow[t]{2}{*}{3 letters } & $\alpha-\operatorname{lac}$ & $98.1(0.5)$ & $97.9(0.5)$ & $97.3(0.4)$ & $96.8(0.5)$ \\
\hline & casein & $97.9(0.5)$ & $98.0(0.4)$ & $96.3(0.5)$ & $97.2(0.5)$ \\
\hline \multirow[t]{2}{*}{6 letters } & $\alpha-\operatorname{lac}$ & $95.9(0.8)$ & $94.3(1.3)$ & $94.2(1.1)$ & $92.8(1.2)$ \\
\hline & casein & $95.7(0.8)$ & $94.4(1.1)$ & $93.0(0.8)$ & $91.4(2.1)$ \\
\hline \multicolumn{6}{|l|}{$\mathrm{RT}$ (ms) } \\
\hline \multirow[t]{2}{*}{2 letters } & $\alpha-\operatorname{lac}$ & $464(13)$ & $465(13)$ & $468(13)$ & $456(14)$ \\
\hline & casein & $456(10)$ & $463(13)$ & $465(15)$ & $467(15)$ \\
\hline \multirow[t]{2}{*}{3 letters } & $\alpha-\operatorname{lac}$ & $489(11)$ & 489 (13) & $503(12)$ & $492(13)$ \\
\hline & casein & $491(15)$ & $480(14)$ & $516(15)$ & $496(15)$ \\
\hline \multirow[t]{2}{*}{6 letters } & $\alpha-\operatorname{lac}$ & $560(18)$ & $567(21)$ & $580(19)$ & $599(29)$ \\
\hline & casein & $570(21)$ & $566(20)$ & $583(19)$ & $594(25)$ \\
\hline \multicolumn{6}{|l|}{ SCWT } \\
\hline \multirow[t]{2}{*}{ Condition I (ms) } & $\alpha$-lac & $476(10)$ & 488 (15) & 478 (14) & $463(13)$ \\
\hline & casein & $473(9)$ & $489(12)$ & $468(13)$ & $454(12)$ \\
\hline \multirow[t]{2}{*}{ Condition II (ms) } & $\alpha$-lac & $563(15)$ & $557(15)$ & $529(15)$ & $515(13)$ \\
\hline & casein & $557(13)$ & $554(14)$ & $537(14)$ & $523(13)$ \\
\hline \multirow[t]{2}{*}{ Condition III (ms) } & $\alpha$-lac & $726(21)$ & $696(23)$ & $699(21)$ & $660(18)$ \\
\hline & casein & $720(21)$ & $710(22)$ & $701(24)$ & $652(20)$ \\
\hline \multirow[t]{2}{*}{ Interference (\%) } & $\alpha$-lac & $39.5(1.9)$ & $32.9(2.5)$ & $38.6(2.2)$ & $35.0(2.0)$ \\
\hline & casein & $40.0(2.9)$ & $36.1(2.8)$ & $39.6(3.6)$ & $33.3(2.7)$ \\
\hline \multicolumn{6}{|l|}{ Left/Right task (ms) } \\
\hline \multirow[t]{2}{*}{ Congruent (fixed) } & $\alpha$-lac & $600(19)$ & $573(21)$ & $607(21)$ & 567 (18) \\
\hline & casein & $604(18)$ & $573(13)$ & $597(21)$ & $564(16)$ \\
\hline \multirow[t]{2}{*}{ Incongruent (fixed) } & $\alpha$-lac & $602(18)$ & $603(19)$ & $624(25)$ & $588(16)$ \\
\hline & casein & 599 (17) & $584(17)$ & $608(23)$ & $586(20)$ \\
\hline Congruent (variable) & $\alpha$-lac & $619(17)$ & $613(15)$ & $629(17)$ & $588(17)$ \\
\hline & casein & $625(14)$ & $607(17)$ & $618(20)$ & $609(18)$ \\
\hline Incongruent (variable) & $\alpha$-lac & $622(16)$ & $624(18)$ & $627(20)$ & $594(14)$ \\
\hline & casein & $637(16)$ & $604(16)$ & $617(19)$ & 606 (18) \\
\hline TOL & & & & & \\
\hline$\%$ correct & & & & & \\
\hline 2 step & $\alpha-\operatorname{lac}$ & $88.6(2.9)$ & $89.1(3.0)$ & $92.2(2.7)$ & $93.3(2.9)$ \\
\hline & casein & $86.8(3.9)$ & $88.6(3.2)$ & $90.5(2.3)$ & $92.2(2.5)$ \\
\hline 3 step & $\alpha-\operatorname{lac}$ & $89.5(2.6)$ & $89.1(3.3)$ & $89.4(1.7)$ & $88.9(3.5)$ \\
\hline & casein & $91.4(2.6)$ & $92.7(1.6)$ & $89.4(2.2)$ & $91.7(2.6)$ \\
\hline 4 step & $\alpha-\operatorname{lac}$ & $77.3(4.2)$ & $78.6(3.8)$ & $86.1(3.3)$ & $83.9(3.1)$ \\
\hline & casein & $81.8(3.3)$ & $79.5(3.7)$ & $81.7(3.2)$ & $84.4(2.4)$ \\
\hline 5 step & $\alpha-\operatorname{lac}$ & $74.1(4.2)$ & $74.5(3.9)$ & $72.8(3.9)$ & $80.0(3.7)$ \\
\hline & casein & $75.0(3.3)$ & $75.5(3.7)$ & $68.3(4.1)$ & $72.2(3.6)$ \\
\hline RT (ms) & & & & & \\
\hline 2 step & $\alpha-\operatorname{lac}$ & $4113(280)$ & 3513 (158) & 4444 (465) & 3784 (234) \\
\hline & casein & 3861 (235) & 3627 (251) & $4273(320)$ & $3710(244)$ \\
\hline 3 step & $\alpha-\operatorname{lac}$ & $4766(290)$ & 4621 (1299) & $5457(325)$ & 5235 (299) \\
\hline & casein & $4931(323)$ & $5007(326)$ & $5649(608)$ & $4834(310)$ \\
\hline 4 step & $\alpha-\operatorname{lac}$ & 6936 (492) & 6690 (407) & $8095(490)$ & $7210(431)$ \\
\hline & casein & $6670(343)$ & 6372 (327) & 8008 (609) & 7006 (442) \\
\hline 5 step & $\alpha-\operatorname{lac}$ & $10819(786)$ & $10010(864)$ & 13384 (1305) & 12365 (1139) \\
\hline & casein & 10915 (703) & $10584(855)$ & 11547 (922) & $11398(874)$ \\
\hline
\end{tabular}

$\alpha-$ lac $=$ alpha-lactalbumin condition; SCWT $=$ Stroop Colour Word Task $; \mathrm{TOL}=$ Tower of London. 

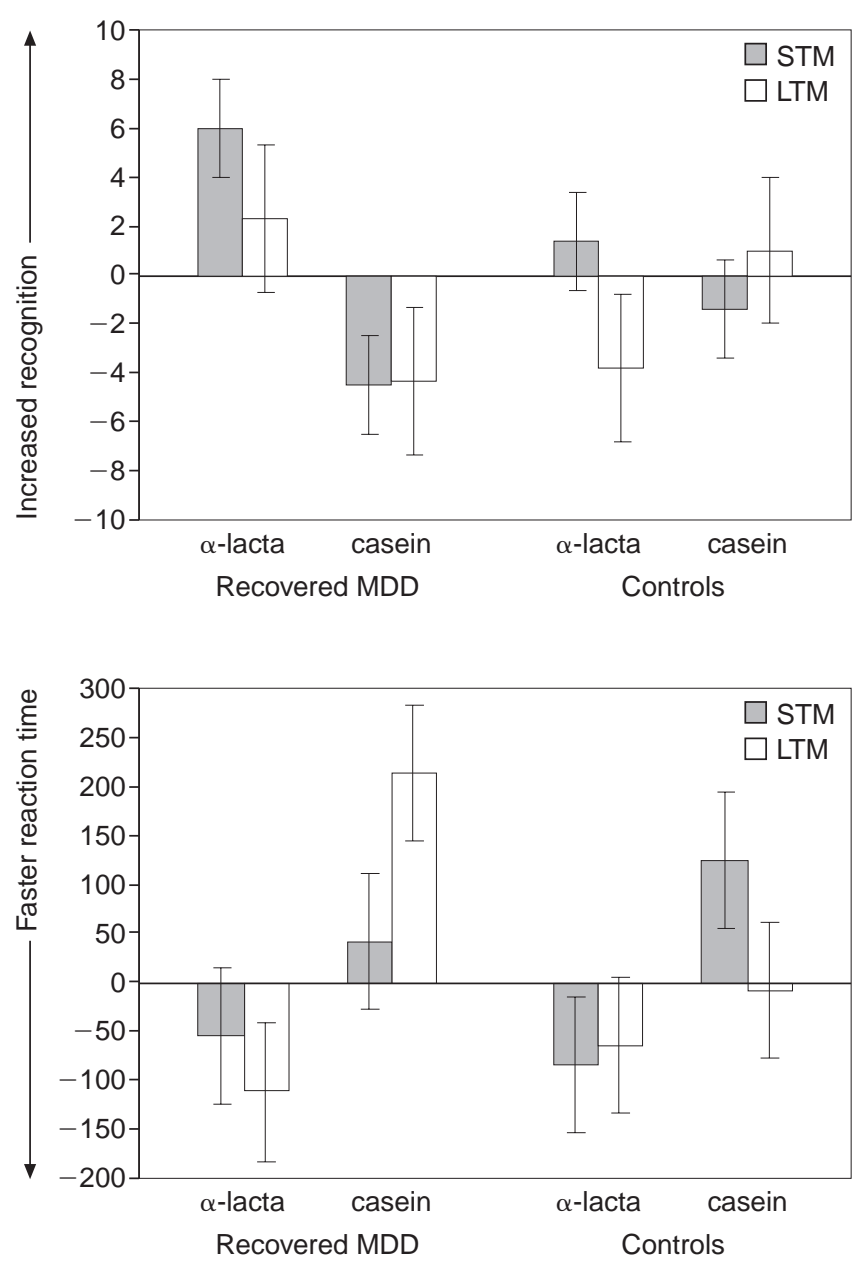

Figures 1 and 2 Mean change (SE) in percentage of correctly recognized patterns (Figure 1, above) and median RT (ms) for correctly recognized patterns (Figure 2, below) for the Abstract Patterns Recognition Task as a function of group and intervention. Scores are changes relative to baseline performance (post - preintervention).

perception or general motor speed. Thus, $\alpha$-lactalbumin may specifically affect memory consolidation in an early phase.

This effect mirrors the consolidation deficit that was found after lowering 5-HT function by tryptophan depletion in healthy volunteers (Riedel et al., 1999; Rubinsztein et al., 2001) and is in line with improved memory after a single dose of citalopram in healthy volunteers (Harmer et al., 2002). Alpha-lactalbumin also improved abstract visual memory in females with premenstrual symptoms (Schmitt et al., 2005). However, it is important to mention that the latter study did not include a control group. Hence, the present study showed that the beneficial effects on memory are not limited to individuals vulnerable to 5-HT related mental disorders. This is of interest because of the fact that the mean age of the participants in the present study was 28.5 years, while cognitive processes usually start to decline around $45-50$ years (Hedden and Gabrieli, 2004: review). Thus abstract visual memory improved even though performance was uncompromised by aging or psychiatric symptoms.

Results might also be (partly) explained by impaired memory in the casein condition. Without a non-intervention control group, these possibilities cannot be separated. Nevertheless, the change of Trp/¿LNAA ratio in the casein condition was comparable to what is usually observed after a balanced meal (Spring et al., 1987; Fischer et al., 2003), which justifies the use of casein as a placebo procedure (Schmitt et al., 2005).

Alpha-lactalbumin impaired motor performance, as shown by an increased number of errors in the fixed interval condition of the Left/Right task, irrespective of group. These results are consistent with previous studies finding decreased performance on simple RT tasks after 5-HT stimulation in patients and in healthy volunteers (Riedel et al., 2002; Sobczak et al., 2003). As intervention had no effect on the number of errors in the more difficult versions of the Left/Right task (variable time intervals) or on working memory tasks (Tower of London/Memory Scanning Task), this suggests that $\alpha$-lactalbumin impaired cognitive performance when the task was relatively easy and monotonous, possibly due to the sleepinducing properties of $\alpha$-lactalbumin (Minet-Ringuet et al., 2004; Markus et al., 2005).

Complex interactions were found on the variable time interval condition of the Left/Right task. RTs improved in the control group after $\alpha$-lactalbumin and remained unchanged after casein. Conversely, in the recovered MDD group, RTs improved after casein but did not change after $\alpha$-lactalbumin. We have no clear explanation for this finding. In the Left/Right task, both task uncertainty (incongruent $v s$. congruent trials) and time uncertainty (fixed $v s$. variable stimulus time intervals) were manipulated. $\alpha$ lactalbumin had no differential effect on the congruent and incongruent trials, a finding consistent with the lack of effect on interference levels on the Stroop Colour Word Task in the present study. Thus, 5-HT did not affect performance in conditions of task uncertainty. No previous studies investigated the effects of 5-HT and/or depression on motor speed as a function of time uncertainty.

The lack of effect on the Memory Scanning Task found in the present study contrasts with the results of Markus et al. (1998, 2002), who reported improved information processing in individuals with high neuroticism scores. Life events and neuroticism are risk factors for major depression, and individuals with high neuroticism have a greater risk of major depression in response to a stressful life event (Kendler et al., 2004). Individuals with high neuroticism may benefit more from an $\alpha$-lactalbumin diet because a high amount of 5-HT activity is required to cope with stress, thereby increasing the risk of a shortage in brain 5-HT concentrations, which increases the risk of depression (Markus et al., 2002). However, about $60 \%$ of the individuals with high neuroticism scores actually became depressed (Ormel et al., 2001). In addition, neuroticism has been shown to be stable over time in adulthood (Kendler et al., 2004). In the present study, most recovered depressed patients had been treated. They may also have coping mechanisms developed through effective treatment, which may reduce the detrimental effects of stress. The neuroticism (N) 
scores of the recovered depressed group in the present study were above average to high (mean $\pm S D: 5.64 \pm 2.3$, range: $2-10$ ), while the control group had low-average scores (mean $\pm S D: 2.60 \pm 2.0$, range $0-8$ ). These group differences are statistically and clinically significant but seem smaller than in Markus et al. (2002), who used a different measure and selected students with $\mathrm{N}$ scores in the lowest and highest quartile of a large subject pool. The results of the present study suggest that high neuroticism and history of depression are different concepts in terms of 5-HT vulnerability.

Mood remained unaffected, which is consistent with the finding that single administration of SSRIs ameliorated emotional processing in healthy volunteers, without changing mood (e.g. Harmer et al., 2003). These findings support our suggestion that cognitive markers may be more sensitive makers for changes in 5HT function than mood or symptom scales (Booij et al., 2005b).

\section{Effect of diet on plasma amino acids and serotonin}

The increases in Trp and ratio Trp/ LLNAA were within similar range as in Schmitt et al. (2005) and Markus et al. (2000, 2002). However, the composition of breakfast and lunch used in Markus et al. (2000, 2002) and Schmitt et al. (2005) contained about three times more calories and two times more carbohydrates than in the present study, whereas the composition of the $\alpha$-lactalbumin or sodium caseinate containing chocolate drink were identical. Thus, the present study demonstrated that $\alpha$-lactalbumin is able to raise Trp levels without necessarily ingesting an excessive amount of carbohydrates, suggesting that $\alpha$-lactalbumin might be relatively easy to implement within a regular diet. A study, reporting an increase of $16 \%$ relative to baseline using an amount of $12 \mathrm{~g}$ $\alpha$-lactalbumin combined with a regular meal, supports this notion (Beulens et al., 2004).

However, as we assessed total Trp concentration and not free Trp, it must be acknowledged that we do not know how much Trp following $\alpha$-lactalbumin actually reaches the brain. Plasma Trp, however, circulates in two forms: either bound to plasma albumin proteins $(80-90 \%)$ or free $(10-20 \%)$. It has been argued that only free-circulating Trp controls the uptake of plasma Trp into the brain, whereas others have suggested that total Trp (plasma free and bound levels) is the most decisive factor. Separate studies have shown that both increases in total plasma Trp (initiated, for instance, by immobilization stress or carbohydrate consumption) and increases in free Trp (initiated, for instance, by physical stress or fasting) may lead to an increase in brain Trp and serotonin activity (Chaouloff, 1993). Moreover, total and free Trp are very closely related, also following an $\alpha$-lactalbumin diet (Attenburrow et al., 2003). In animals, administration of $\alpha$-lactalbumin increased baseline extracellular 5-HT in the hypothalamus, indicating that $\alpha$-lactalbumin not only enhance 5-HT synthesis but also its release (Orosco et al., 2004). In humans, increases of $20-40 \%$ in ratio $\operatorname{Trp} / \sum$ LNAA led to significant increases in peripheral markers of 5-HT activity, including cortisol and prolactin (Kaye et al, 1988; Anderson et al., 1990; Markus et al., 2000).

Changes in mood and cognitive performance might also be related to raised plasma tyrosine levels, as catecholamines are involved in mood and cognitive processes as well (Booij et al., 2003: review). The effects on catecholamine precursor levels in the $\alpha$-lactalbumin condition are probably negligible - in fact, the tyrosine/LNAA ratio decreased slightly. The rise in the casein condition was higher, which is not surprising as this diet contained less tryptophan and twice the amount of tyrosine (Markus et al., 2000, table 2; Markus et al., 2002, table 2). No other $\alpha$-lactalbumin experiments have reported tyrosine/ $\sum$ LNAA ratios. In healthy samples, tyrosine administration improved Stroop performance and working memory (Deijen and Orlebeke, 1994), however we found no intervention effect on working memory tasks. Similarly, a memory consolidation deficit was induced by ATD and not by Acute Phenylalanine Tyrosine Depletion (APTD), whereas a working memory deficit was induced by APTD and not by ATD (Harrison et al., 2004). High-dose ATD (100 g) markedly decreases Trp levels and 5-hydroxyindoleacetic acid (5-HIAA), but also induces an increase $(50 \%)$ of tyrosine/ 2 LNAA levels however, homovanillic acid (HVA) remains unaffected, measured either in cerebrospinal fluid (Carpenter et al., 1998) or plasma (Van der Does et al., 2005). Nevertheless, it is recommended to investigate the biochemical specificity further by combining $\alpha$-lactalbumin-enriched diets with monoaminergic depletion paradigms and to develop alternative placebo procedures.

In conclusion, diet enriched with $\alpha$-lactalbumin enhanced memory, irrespective of history of depression. Mood and other cognitive functions remained unaffected. As 5-HT activity is reported to decline with aging (McEntee and Crook, 1991), the present findings could be further examined in older samples. The long-term effects of $\alpha$-lactalbumin should also be investigated.

\section{Acknowledgements}

The Netherlands Organization of Sciences-Medical Sciences (NWO-MW) grant 904-57-132 to Professor Van der Does facilitated the preparation of this study. Tryptophan-rich $\alpha$-lactalbumin protein was provided by Friesland Coberco Dairy Foods (Deventer, the Netherlands). The authors thank Martine Blok, MSc, Iris Bulthuis, MSc and Ilse Van der Meij, MSc for assistance with the data collection and the laboratory and staff of the Department of Psychiatry and Paediatrics of Leiden University Medical Centre for technical assistance. Linda Booij, $\mathrm{PhD}$ is now at the Department of Psychiatry, McGill University, Montreal, Canada.

\section{References}

Anderson I M, Parry-Billings M, Newsholme E A, Fairburn C G, Cowen P J (1990) Dieting reduces tryptophan and alters brain 5-HT function in women. Psychol Med 20: 785-791

Attenburrow M J, Williams C, Odontiadis J, Reed A, Powell J, Cowen P J, Harmer C J (2003) Acute administration of nutritionally sourced tryptophan increases fear recognition. Psychopharmacology (Berl) 169: 104-107

Austin M P, Mitchell P, Goodwin G M (2001) Cognitive deficits in depression: possible implications for functional neuropathology. Br J Psychiatry 178: 200-206

Beck A T, Steer R A, Brown G K (1996) Manual for the Beck Depression Inventory II. The Psychological Corporation, San Antonio, TX

Benton D, Nabb S (2003) Carbohydrate, memory, and mood. Nutr Rev 61: S61-S67

Beulens J W J, Bindels J G, de Graaf C, Alles M S, Wouters-Wesseling W 
(2004) Alpha-lactalbumin combined with a regular diet increases plasma Trp-LNAA ratio. Physiol Behav 81: 585-593

Booij L, Van der Does A J W, Riedel W J (2003) Monoamine depletion in psychiatric and healthy populations: review. Mol. Psychiatry 8: 951-973

Booij L, Van der Does A J W, Haffmans P M J, Spinhoven Ph, McNally R J (2005a). Acute tryptophan depletion as a model of depressive relapse: behavioral specificity and ethical considerations. Br. J. Psychiatry $187: 148-154$.

Booij L, Van der Does A J W, Haffmans P M J, Riedel W J, Fekkes D, Blom M J B (2005b) The effects of high-dose and low-dose tryptophan depletion on mood and cognitive functions of remitted depressed patients. J Psychopharmacol 19: 267-276

Burt D B, Zembar M J, Niederehe G (1995) Depression and memory impairment: a meta-analysis of the association, its pattern, and specificity. Psychol Bull 117: 285-305

Carpenter L L, Anderson G M, Pelton G H, Gudin J A, Kirwin P D, Price L H, Heninger G R, McDougle C J (1998) Tryptophan depletion during continuous CSF sampling in healthy human subjects. Neuropsychopharmacology 19: 26-35

Chaouloff F (1993) Physiopharmacological interactions between stress hormones and central serotonergic systems. Brain Res Brain Res Rev 18: $1-32$

Chouinard G, Young S N, Annable L (1985) A controlled clinical-trial of L-tryptophan in acute mania. Biol Psychiatry 20: 546-557

Deijen J B, Orlebeke J F (1994) Effect of tyrosine on cognitive function and blood-pressure under stress. Brain Research Bulletin 33: 319-323

Dye L, Lluch A, Blundell J E (2000) Macronutrients and mental performance. Nutrition 16: 1021-1034

Eysenck H J, Eysenck S B G (1991) Manual of the Eysenck Personality Scales. Hodder \& Stoughton, London

Fernstrom J D, Wurtman R J (1972) Brain serotonin content: physiological regulation by plasma neutral amino acids. Science 178: 414-416

First M B, Spitzer R L, Gibbon M, Williams J B W (1995). Structured clinical interview for DSM-IV Axis I Disorders. (Patient ed. (SCIDI/P)). Biometrics Research Department, NYSPI, New York

Fischer K, Colombani P C, Langhans W, Wenk C (2003) Carbohydrate to protein ratio in food and cognitive performance in the morning. Physiol Behav 75: 411-423

Gibson E L, Green M W (2002) Nutritional influences on cognitive function: mechanisms of susceptibility. Nutr Res Rev 15: 169-206

Harmer C J, Bhagwagar Z, Cowen P J, Goodwin G M (2002) Acute administration of citalopram facilitates memory consolidation in healthy volunteers. Psychopharmacology (Berl) 163: 106-110

Harmer C J, Bhagwagar Z, Perrett D I, Vollm B A, Cowen P J, Goodwin G M (2003) Acute SSRI administration affects the processing of social cues in healthy volunteers. Neuropsychopharmacology 28: 148-152

Harrison B J, Olver J S, Norman T R, Burrows G D, Wesnes K A, Nathan P J (2004) Selective effects of acute serotonin and catecholamine depletion on memory in healthy women. J Psychopharmacol 18: 32-40

Hedden T, Gabrieli J D E (2004) Insights into the ageing mind: A view from cognitive neuroscience. Nat Rev Neurosci 5: 87-U12

Heine W, Radke W, Wutzke K D, Peters E, Kundt G (1996) Alphalactalbumin-enriched low-protein infant formulas: A comparison to breast milk feeding. Acta Paediatr 85: 1024-1028

Kaye W H, Gwirtsman H E, Brewerton T D, George D T, Wurtman R J (1988) Bingeing behavior and plasma amino acids: a possible involvement of brain serotonin in bulimia nervosa. Psychiat Res 23: 31-43.

Kendler K S, Kuhn J, Prescott C A (2004) The interrelationship of neuroticism, sex, and stressful life events in the prediction of episodes of major depression. Am J Psychiatry 161: 631-636
Kessing L V (1998) Cognitive impairment in the euthymic phase of affective disorder. Psychol Med 28: 1027-1038

Markus C R, Jonkman, L M, Lammers, J H C M, Deutz N E P, Messer, M $\mathrm{H}$, Rigtering, N H (2005) Evening intake of alpha-lactalbumin increases plasma tryptophan availability and improves morning alertness and brain measures of attention. Am J Clin Nutr 81: 1026-1033.

Markus C R, Olivier B, de Haan E H F (2002) Whey protein rich in alphalactalbumin increases the ratio of plasma tryptophan to the sum of the other large neutral amino acids and improves cognitive performance in stress-vulnerable subjects. Am J Clin Nutr 75: 1051-1056

Markus C R, Olivier B, Panhuysen G E M, Van der Gugten J, Alles M S, Tuiten A, Westenberg H G M, Fekkes D, Kopeschaar H F, De Haan E E H F (2000) The bovine protein alpha-lactalbumin increases the plasma ratio of tryptophan to the other large neutral amino acids, and in vulnerable subjects raises brain serotonin activity, reduces cortisol concentration, and improves mood under stress. Am J Clin Nutr 71 1536-1544

Markus C R, Panhuysen G, Tuiten A, Koppeshaar H, Fekkes D, Peters M L (1998) Does carbohydrate-rich, protein-poor food prevent a deterioration of mood and cognitive performance of stress-prone subjects when subjected to a stressful task? Appetite 31: 49-65

McEntee W J, Crook T H (1991) Serotonin, memory, and the aging brain. Psychopharmacology (Berl) 103: 143-149

McNair D M, Lorr M, Droppelamn L F (1971) Edits manual for the profile of mood states. Educational and Industrial Testing Service, San Diego, CA

Merens W, Booij L, Markus C R, Zitman F G, Van der Does A J W (2005) The effects of a diet enriched with $\alpha$-lactalbumin on mood, stress and cognitive functions in recovered depressed patients. Br J Nutr, in press

Minet-Ringuet J, Le Ruyet P M, Tome D, Even P C (2004) A tryptophanrich protein diet efficiently restores sleep after food deprivation in the rat. Behav Brain Res 152: 335-340

Montgomery S A, Asberg M (1979) A new depression scale designed to be sensitive to change. Br J Psychiatry 134: 382-389

Ormel J, Oldehinkel A J, Brilman E I (2001) The interplay and etiological continuity of neuroticism, difficulties, and life events in the etiology of major and subsyndromal, first and recurrent depressive episodes in later life. Am J Psychiatry 158: 885-891

Orosco M, Rouch C, Beslot F, Feurte S, Regnault A, Dauge V (2004) Alpha-lactalbumin-enriched diets enhance serotonin release and induce anxiolytic and rewarding effects in the rat. Behav Brain Res 148: 1-10

Owen A M, Sahakian B J, Semple J, Polkey C E, Robbins T W (1995) Visuo-spatial short-term recognition memory and learning after temporal lobe excisions, frontal lobe excisions or amygdalo-hippocampectomy in man. Neuropsychologia 33: 1-24

Paradiso S, Lamberty G J, Garvey M J, Robinson R G (1997) Cognitive impairment in the euthymic phase of chronic unipolar depression. J Nerv Ment Dis 185: 748-754

Pollack I, Norman D A (1964) A non-parametric analysis of recognition experiments. Psychon Sci 1: 125-126

Riedel W J, Klaassen T, Deutz N E, van Someren A, Van Praag H M (1999) Tryptophan depletion in normal volunteers produces selective impairment in memory consolidation. Psychopharmacology (Berl) 141: 362-369

Riedel W J, Klaassen T, Griez E, Honig A, Menheere P P C A, Van Praag H M (2002) Dissociable hormonal, cognitive and mood responses to neuroendocrine challenge: Evidence for receptor-specific serotonergic dysregulation in depressed mood. Neuropsychopharmacology 26: 358-367

Rubinsztein J S, Rogers R D, Riedel W J, Mehta M A, Robbins T W, Sahakian B J (2001) Acute dietary tryptophan depletion impairs maintenance of 'affective set' and delayed visual recognition in healthy volunteers. Psychopharmacology (Berl) 154: 319-326 
Sanderman R, Arrindell W A, Ranchor A V, Eysenck H J, Eysenck S B G (1995) Eysenck Personality Questionnaire (EPQ). NCvG, Rijksuniversiteit Groningen

Schmitt J A, Jorissen B L, Dye L, Markus C R, Deutz N E P, Riedel,W J. (2005) Memory function in women with premenstrual complaints and the effect of serotonergic stimulation by acute administration of an alpha-lactalbumin protein. J Psychopharmacol, 19: 375-384

Schmitt J A, Jorissen B L, Sobczak S, van Boxtel M P, Hogervorst E, Deutz N E, Riedel W J (2000) Tryptophan depletion impairs memory consolidation but improves focussed attention in healthy young volunteers. J Psychopharmacol 14: 21-29

Sobczak S, Honig A, Schmitt J A J, Riedel W J (2003) Pronounced cognitive deficits following an intravenous L-tryptophan challenge in firstdegree relatives of bipolar patients compared to healthy controls. Neuropsychopharmacology 28: 711-719

Spring B, Chiodo J, Bowen D J (1987) Carbohydrates, tryptophan, and behavior - a methodological review. Psychol Bull 102: 234-256
Sternberg S (1969) Memory-scanning: mental processes revealed by reaction-time experiments. Am Sci 57: 421-457

Stevens J (1996) Applied multivariate statistics for the social sciences, 3rd edn. Lawrence Erlbaum, Hillsdale, NJ

Van der Does A J W (2001) The effects of tryptophan depletion on mood and psychiatric symptoms. J Affect Disord 64: 107-119

Van der Does A J W, Booij L (2005) Cognitive therapy does not prevent a response to tryptophan depletion in patients also treated with antidepressants. Biol Psychiatry, in press

Wald F D M, Mellenbergh G J (1990) De verkorte versie van de Nederlandse vertaling van de Profile of Mood States (POMS). Ned Tijdschr Psychol 45: 86-90

Weiland-Fiedler P, Erickson K, Waldeck T, Luckenbaugh D A, Pike D, Bonne O, Charney D S, Neumeister A (2004) Evidence for continuing neuropsychological impairments in depression. J Affect Disord 82: $253-258$ 